\title{
Gravity measurements in the Pieniny Klippen Belt (Western Slovakia)
}

\author{
Jana Bučovát, ${ }^{1,2}$, Miroslav Bielik², Roman Pašteka ${ }^{3}$, Dušan Plašienka ${ }^{4}$ \\ ${ }^{1}$ Slovak Academy of Sciences, Geophysical Insitute; Dúbravská cesta 9, 84504 Bratislava, Slovakia; \\ e-mail:geofjabu@savba.sk \\ ${ }^{2}$ GEOFOS, s.r.o.; Velký diel 3323, 01008 Žilina, Slovakia \\ ${ }^{3}$ Comenius University, Faculty of Natural Sciences, Department of Applied and Environmental Geophysics; \\ Mlynská dolina, 84215 Bratislava 4, Slovakia \\ ${ }^{4}$ Comenius University, Faculty of Natural Sciences, Department of Geology and Paleontology; \\ Mlynská dolina, 84215 Bratislava 4, Slovakia
}

(C) 2015 Authors. This is an open access publication, which can be used, distributed and reproduced in any medium according to the Creative Commons CC-BY 4.0 License requiring that the original work has been properly cited.

The examined area is situated in the Púchov section of the Pieniny Klippen Belt (PKB) in western Slovakia. The main aim of our research was to broaden the present knowledge on geological structure of the PKB and on its tectonic connection to the surrounding regional units using the geophysical methods.

The profile gravity measurements consist of two parallel profiles named prof_1 and prof_2 of roughly NNW-SSE direction. The eastern section prof_1 has a length of $6.36 \mathrm{~km}$; the western profile prof_2 is about $3.84 \mathrm{~km}$ long. Measurements were carried out at intervals of 20 meters (overall 506 points were gauged) by gravimeters Scintrex CG3 and CG5. The acquire data were processed into the Bouguer gravity anomalies. The software package GM-SYS (Geosoft) was applied for the gravity modelling and the final geological-geophysical sections represent distribution of the lithological members with their specific density parameters (density values were determined by the own laboratory measurements of rock samples collected along the profiles). The density modelling was also based on the results obtained by the geoelectrical exploration (vertical electric sounding and resistivity profiling), new surface geological mapping and borehole interpretation (continuously cored bores MIK-1 and MIK-2).

Presented detailed gravity measurements reflect density differences between klippen (rigid limestone blocks) and their mantle (predominant marlstone) and they demonstrate that the primary fold-nappe system of the PKB was destructed by the subsequent deformation, resulting in the formation of the positive flower structure and backthrusting. Summing up, the new density modelling confirmed complex geological structure of the studied area and helped us to better interpret the tectonic evolution of the PKB.

The authors are thankful to the Slovak Research and Development Agency (grants APVV-0465-06, $A P V V-0212-12$ and LPP-0225-06). 